\title{
Using Digital Devices in a First Year Classroom: A Focus on the Design and Use of Phonics Software Applications
}

\author{
Maria Nicholas ${ }^{1}$, Sophie McKenzie ${ }^{2} \&$ Muriel A. Wells ${ }^{1}$ \\ ${ }^{1}$ School of Education, Faculty of Arts and Education, Deakin University, Geelong, Australia \\ ${ }^{2}$ School of Information Technology, Faculty of Science, Engineering \& Built Environment, Deakin University, \\ Geelong, Australia \\ Correspondence: Maria Nicholas, School of Education, Faculty of Arts and Education, Deakin University, \\ Geelong, Australia. Tel: 61-3-5227-1472. E-mail: maria.n@deakin.edu.au
}

Received: October 18, 2016

Accepted: November 30, $2016 \quad$ Online Published: December 12, 2016

doi:10.5539/jel.v6n1p267

URL: http://dx.doi.org/10.5539/jel.v6n1p267

\begin{abstract}
When integrated within a holistic literacy program, phonics applications can be used in classrooms to facilitate students' self-directed learning of letter-sound knowledge; but are they designed to allow for such a purpose? With most phonics software applications making heavy use of image cues, this project has more specifically investigated whether the design of the images used in such applications may impact on the effectiveness of their self-directed use in classrooms. Using a quasi-experimental study, we compared two types of pictorial mnemonics used in tablet applications, along with teacher-led activity in three first-year classrooms from the one school. The difference between teacher-led activity and integrated picture cues was significant, with teacher-led activity proving more effective. The difference between teacher-led activity and form-taking picture cues, however, was not statistically significant. Given that the outcomes of this small-scale study suggest that image design may be a significant design feature contributing to the educational value of using phonics applications in the classroom, we recommend that the design features of phonics software applications attract further research.
\end{abstract}

Keywords: phonics, digital, technology, learning, teaching, early years, design, discourse

\section{Introduction}

Increased accessibility to digital technologies in schools has meant that teachers have been provided with alternatives to teaching that have paved the way for possible changes to their pedagogical practices (Hedberg, 2011). In this study, we explore how digital technologies can be used in Foundation classrooms (the first year of schooling in Australia), to facilitate self-directed learning of lower-order, "closed" knowledge; a practice that has the potential to free teachers to devote more of their time engaging students in more meaningful teaching and learning activities. This paper responds to a move towards a "value added approach" to the research of digital technologies in education ("which features [of the software program and/or device] lead to learning?") rather than a question of "effectiveness" per se (Clark \& Mayer, 2011, p. 380). Specifically, our purpose was to investigate whether the type of pictorial representations used in phonics applications may be a significant design feature in software designed to support young learners to match letters to sounds, and whether larger-scale, more rigorous research on their design would be warranted.

Learning the most common letter-sound association (Note 1) is considered a constrained skill (Pfost, Hattie, Dörfler, \& Artelt, 2014) given the closed, correct-or-incorrect nature of this knowledge. Yet this knowledge has been found to be critical in assisting children to develop early reading skills (Australian Government: Department of Education, 2005; National Early Literacy Panel, 2008; Stanovich, 1986). Traditional drill and practice has been found to be an effective avenue through which to acquire and retain closed knowledge in memory (Joseph, Eveleigh, Konrad, Neef, \& Volpe, 2012; Kirriemuir \& McFarlane, 2006; Musti-Rao, Lo, \& Plati, 2014; Yu, Liu, \& Chan, 2005), yet it is questionable whether this is an effective use of teacher time when such a practice may be facilitated via other means (Jones, 2009; Kirriemuir \& McFarlane, 2006; Musti-Rao et al., 2014). Digital technologies provide an alternative means by which to engage learners in self-directed drill and practice, working as a tutor by providing users with individualised feedback as they interact with software (Jones, 2009; Musti-Rao et al., 2014). Use of digital technology in this way, with small groups of children, has the 
potential to release teachers to engage with others in learning experiences that encourage contextualised, deeper levels of thinking with or without the aid of digital technologies.

Many studies have investigated the effectiveness of using computer aided instruction to support young children to acquire early reading skills, with the findings presented across studies proving inconclusive (Cassady \& Smith, 2005; Kartal \& Terziyan, 2016; Korat \& Blau, 2010; Macaruso \& Walker, 2008; Nicolson, Fawcett, \& Nicolson, 2000; Paterson, Henry, O'Quin, Ceprano, \& Blue, 2003). These studies explored the development of more open-ended reading skills such as comprehension and fluency, some considered variations in the strategies teachers used, while others included investigations into whether time on task would have an influence on a computer program's effectiveness. Our study contributes to this body of research and seeks more conclusive findings by focusing on one design feature (pictorial cues) and a closed reading skill (common letter-sound mapping). The outcomes of our study have led us to conclude that when teaching approaches and student demographics are similar, and when time on task remain constant, there is sufficient evidence to suggest that the images that are used to support the learning of common letter-sound associations may have a significant impact on student learning, calling for further research into the design of phonics applications. We suggest that this is due to a possible misalignment between discourse and design.

Kress and Van Leeuwen (2001) and Darcy and Auld (2008) describe four domains of practice through which multimodal texts such as those provided via electronic platforms make meaning: discourse, design, production and distribution. Discourses, as defined by Kress and Van Leeuwen (2001, p. 4) are "socially constructed knowledges". Design transforms those knowledges into "social (inter-) action" (Kress \& Van Leeuwen, 2001, p. 5). Using Kress and Van Leeuwen's description of the relationship that exists between these two domains, it can be argued that it is essential that discourse (here referring to theories of memory retention and the successful learning of letter-sound mapping) is actualised through the design of a digital software application, in order to achieve maximum educational value. When software design is motivational and appealing, with limited consideration for the cognitive processes required to foster learning, software runs the risk of falling within the "high behavioural activity/low psychological activity" quadrant of Clark and Mayer's (2011, p. 370) e-learning "activity matrix", stimulating little of the psychological activity that is required for learning.

In this paper, we describe the discourses which informed the design of two letter-sound mapping software applications we created and trialled in this study (see also: "Acknowledgements"), before detailing the method used to compare the applications against teacher-led drill and practice. We conclude that there is sufficient evidence to suggest that the alignment of discourse and design is critical to the effective integration of digital technologies in early years classrooms when used as self-directed tasks, warranting further research into phonics software design.

\subsection{Background}

This section describes the theoretical concepts that informed the design of the two software applications used in this study, beginning with our choice of target content.

\subsubsection{Early Reading Skills}

In his seminal paper, Stanovich (1986) identified that a causal link exists between phonological awareness and reading acquisition, and more specifically that "conscious access to the phonemic level of the speech stream" enables early reading success (Stanovich, 1986, p. 362); a proposition that has been supported in subsequent studies (Ehri et al., 2001; Høien, Lundberg, Stanovich, \& Bjaalid, 1995; Hulme et al., 2002; Jongejan, Verhoeven, \& Siegel, 2007; Muter, Hulme, Snowling, \& Taylor, 1998). Stanovich cautioned however, that phonological awareness and the skill of letter-sound mapping need be acquired early in order to circumvent "a causal chain of escalating negative side effects" (1986, p. 364); a theory recently supported by Pfost et al. (2014), having conducted a review of longitudinal studies into reading skill acquisition and development.

Perfetti (1991) suggested that it is computational knowledge (letter-sound mapping) more so than reflective knowledge ("conscious manipulation of the components of spoken words" (pp. 38-39)) that is critical in the early stages of reading acquisition. This suggestion has also been reflected in a meta-analytic review conducted by Melby-Lervåg, Lyster, and Hulme (2012) who found that phonemic awareness showed the strongest correlation and was a "unique predictor of individual differences in children's word reading skills" (p. 340) even after controlling for the effects of rime awareness and verbal short-term memory. Stanovich (1986) referred to the temporal relationship between phonemic awareness and reading acquisition as the "Matthew effect", describing the growing gap in abilities between less advanced readers and their more able peers as they progress through their schooling. 
The proposition that delayed letter-sound acquisition may lead to the delayed acquisition of other reading related skills, such as whole word recognition and the ability to gain meaning from text has had much support (Australian Government: Department of Education, 2005; National Early Literacy Panel, 2008; National Reading Panel, 2000; Rowe, 2005). These findings influenced our choice to focus on letter-sound mapping for this study. How to assist children to acquire this knowledge as quickly and effectively as possible is an area of research we turned to next.

\subsubsection{Drill and Practice}

The learning and recall of basic, "constrained" (Pfost et al., 2014, p. 209) knowledge, such as commonly used letter-sound mapping or high frequency sight words can be effectively facilitated via tasks that plan for repeated exposure and rehearsal, often referred to as "drill and practice" (Joseph et al., 2012; Musti-Rao et al., 2014; Yu et al., 2005). Studies that have found drill and practice to be less effective than other teaching strategies, have focused on knowledge that is process based (e.g., addition, or the reading of passages of text) rather than constrained knowledge alone (Musti-Rao et al., 2014; Tournaki, 2003). While there is some criticism for drill and practice (Booker, 2007), when strategically incorporated into a holistic, multi-faceted curriculum that integrates contextualisation, process and knowledge acquisition, drill and practice can facilitate the recall of constrained knowledge, which more cognitively demanding processes of thinking can build upon (Booker, 2007; Pfost et al., 2014; Seaman, 2011).

It is recognised that knowledge is personalised, often differing to the knowledge held by others (Cobb, 1994; Nicholas \& Paatsch, 2014). It can therefore be appreciated why early users of digital technologies in education, acknowledging this newfound avenue through which to individualise learning, made use of drill and practice for closed "pre-determined learning goals", offering users instant feedback as they engaged in "self-paced learning" (Jones, 2009, n.p). The use of digital technologies is not restricted to tasks that require the individualised rehearsal of pre-determined outcomes however. Since the 1970s, beginning with the introduction of "computer-mediated communication" there has been an appreciation that digital technologies can also be used to facilitate thinking processes that require collaboration, scaffolding and shared experiences (Jones, 2009, n.p).

Higher order thinking tends to require more teacher input as engagement in open learning requires more guidance, problem solving, judgement and contextualised adaptation. It is for this reason that Kirriemuir and McFarlane (2006) caution that while:

...drill and practice' is a proven principle of education and learning..., it is questionable whether such activities should occupy a significant part of the school day, where children have access to teachers, resources and more demanding and creative learning tasks (p. 25).

There is now growing appreciation for the fact that the integration of new technologies into the classroom, such as the use of digital mobile devices has provided teachers with greater means by which to diversify their teaching and provide positive changes to pedagogical practices (Hedberg, 2011). When the rehearsal and recall of constrained content knowledge can be facilitated independently of the teacher following some initial instruction, this frees the teacher to devote more time to the teaching of more cognitively demanding elements such as those listed by Yu et al. (2005) and Seaman (2011) including elaboration, organisation, evaluation, analysis and synthesis. When strategically introduced by the teacher as an additional and complementary avenue through which to target specific content knowledge (Cheung \& Slavin, 2012; Flewitt, Messer, \& Kucirkova, 2014), there is good argument for using phonics applications in the classroom.

\subsubsection{Digital Technologies in the Classroom}

Handheld digital devices are now common artefacts that are often used both in class and out by primary school aged children and many of their younger counterparts (Danby et al., 2013; Given et al., 2014; Walsh, 2011), with tablets and hand-held devices identified as the most commonly used devices amongst 3-5 year olds (Given et al., 2014). Whether or not children have access to digital technologies in their homes, digital devices can provide a highly stimulating and motivational environment for young students, with applications designed to support children's literacy development demonstrating positive outcomes for users (Flewitt et al., 2014; McManis \& Gunnewig, 2012; Reid \& Ostashewski, 2011).

Watlington (2011) and Reid and Ostashewski (2011) highlight the new possibilities readily available through the use of tablet devices, when one considers how new functionalities (e.g., taps, swipes and pinch-zooms), coupled with a light, robust textbook-size screen have paved the way for the development of thousands of specifically designed educational applications. Comparing traditional classroom media to digital media, Stern (2014) and Flewitt et al. (2014) found that young learners have a preference for the digital. While the authors noted that 
digital presentation of content can be considered novel by young learners, it was the broader preference for "dynamic visual content, a high degree of interactivity, and the presence of multimodal interaction" (Stern, 2014, p. 923) that attracted students to tablet devices. Further to this, Neumann (2016), Ihmeideh (2014) and Noorhidawati, Ghalebandi, and Hajar (2015) have all presented findings that indicate that the use of mobile devices can encourage more than engagement, with their collective research outcomes indicating that mobile devices can also allow for cognitive, psychomotor-based and affective learning.

As highlighted by Cheung and Slavin (2012) however, use of digital technologies in classrooms is most successful when partnered with teacher instruction. Teacher attitude is also critical with positive attitudes towards the adoption of digital technologies playing a key role (Blackwell, Lauricella, \& Wartella, 2014). Principals (headmasters) and classroom teachers ultimately determine the adoption of digital technologies and associated applications in classrooms, more so than availability on its own (De Grove, Bourgonjon, \& Van Looy, 2012; Flewitt et al., 2014; Reid \& Ostashewski, 2011). There is therefore a need to provide teachers with complementary professional development in suitable approaches to support children's literacy and language development (Landry, Swank, Anthony, \& Assel, 2011). With a multitude of phonics applications available, it is essential that teachers are not only attracted to the potential for self-efficacy that such applications provide, but can also appreciate how particular applications successfully combine discourse and design (Kress \& Van Leeuwen, 2001) to support their programs as a whole.

Stern (2014), Flewitt et al. (2014) and Reid and Ostashewski (2011) suggest that careful consideration must be given to both interaction-based elements and content-based material, when designing content for presentation on digital devices for young learners. They suggest that the design should support both interactive and independent learning experience, that feedback be clear, immediate and rewarding, and that distractors that divert attention from the primary content must be minimised. Though the final point included the elimination of links to social media and other such distractors, this suggestion has a strong connection with research that has investigated theories into the effective retrieval of target memories, and the theory of "interference".

\subsubsection{Dual Coding Theory}

Digital technologies allow for a variety of modes through which to present target content; and with this, a variety of mode through which to introduce potential distractors. When designing the gaming applications to be trialled in our study, we needed to make considered decisions that would ensure that our designs were aligned with discourses on how children acquire phonemic knowledge, while planning to minimise any foreseeable distractors. The alphabet, or any target content for that matter, can be difficult to recall for a number of reasons. According to Levin (1993) there are four main factors; the amount to be remembered, unfamiliarity, the complexity of the content and abstractness. In the case of the alphabet, it could be argued that all of the above apply. This is not surprising given that research into the origins of the alphabet has found that its Hebrew, Greek, German and Gaelic creators at least, considered the alphabet a mnemonic device, used to aid and as a substitute for memory so that communication was not constrained by the capacity of the human mind or a particular time or place (Stecchini, 1961).

Over the past 30 years it has been noted that several studies have sought to investigate how the learning of letter sound associations may be effectively facilitated through the strategic use of pictorial mnemonics. The focus on pictorial mnemonics appears to have been influenced by supporters of Paivio and Csapo (1973) who postulated that the visual mnemonic's effectiveness might be due to "dual coding theory". Dual coding theory is based upon the assumption that the memory utilises two encoding systems; one is visual and relates to concrete things referred to as imagens, the other being verbal and relating to abstract linguistic units referred to as logogens (Paivio \& Csapo, 1973; Sadoski \& Paivio, 2013). It is theorised that these systems can work independently or jointly for "encoding, storage, organization and retrieval of stimulus information" (Paivio \& Csapo, 1973, p. 177).

When learning letter-sound associations, this theory suggests that the abstract letter shape that is used to symbolise a unit or units of sound will be more effectively stored, organised and retrieved from memory if it is associated with a visual connection (e.g., the symbol "a" and sound /a/ are associated with an image of an apple). Attempting to connect an abstract logogen (the symbol of the letter) to another abstract logogen (a unit or units of sound) without the additive benefit of an imagen demands that memory rely heavily on only one encoding system. This theory assigns the visual memory cue with superior additive properties, positing that if one code fails there is another that can be used to retrieve the sought after information (Kuo \& Hooper, 2004; Paivio \& Csapo, 1973). 


\subsubsection{Pictorial Mnemonics}

Reviewing the literature on pictorial mnemonics used to facilitate letter-sound mapping, we came to identify three distinct pictorial categories used across the studies:

a) The disassociated: Pictorial mnemonics of recognisable objects in their natural state are used to facilitate recall. The letter symbol does not occupy the same space as the image (de Graaff, Bosman, Hasselman, \& Verhoeven, 2009; Ehri, Deffner, \& Wilce, 1984; Manalo, Uesaka, \& Sekitani, 2013; Shmidman \& Ehri, 2010);

b) The form takers: Pictorial mnemonic cues take on the form of their corresponding letter symbol. As with the disassociated cue, the letter symbol does not occupy the same space as the image (Dilorenzo, Rody, Bucholz, \& Brady, 2011; Gregory, 1984) (Note 2);

c) The integrated: Pictorial mnemonic cues and their corresponding letter symbols are combined so that the image and letter symbol are identifiable while occupying the same space (Agramonte \& Belfiore, 2002; de Graaff et al., 2009; de Graaff, Verhoeven, Bosman, \& Hasselman, 2007; Dilorenzo et al., 2011; Ehri et al., 1984; Fulk, Lohman, \& Belfiore, 1997; Gregory, 1984; Hoogeveen, Smeets, \& Lancioni, 1989; Manalo et al., 2013; Sener \& Belfiore, 2005; Shmidman \& Ehri, 2010).

These studies investigated the acquisition of letter-sound knowledge with English first language users, Dutch first language users, Turkish students learning the English language, English language users learning the Hebrew alphabet and Japanese students learning the English language. It was de Graaff et al. (2007) who first began to explore the effectiveness of using artificially embedded pictorial mnemonics within an electronic environment with a follow-up study conducted two years later (de Graaff et al., 2009).

In most of the studies listed above, the pictorial cues used across categories have been chosen to represent nouns which begin with the same initial unit of sound (phoneme) as the most common sound represented by their corresponding letter symbols (graphemes). For example, though the letter "g" can be representative of the phoneme /j/ (e.g., "giraffe"), an image of a pair of "glasses" is used to remind its user that the grapheme "g" most commonly represents the /g/ phoneme in the English language (Ehri et al., 1984).

With the exceptions of Dilorenzo et al. (2011) and Gregory (1984) who made use of a mixture of the second and third categories, the above named authors chose the integrated mnemonic as their main focus of inquiry. There are varying degrees to which an image and corresponding letter symbol may be integrated however, pointing to a possible mismatch in the way in which "integration" and/or "embedment" has been understood and used by each author. This finding prompted us to address this oversight in the literature through a valued-added study which has investigated whether the design of images used in self-directed phonics software applications must be more distinctly integrated with the letter symbol they are to represent in order to minimise potential distractors.

\begin{tabular}{|c|c|c|c|c|}
\hline Form Taking & $\begin{array}{l}3 \text { Degrees of } \\
\text { Integration }\end{array}$ & $\begin{array}{l}2 \text { Degrees of } \\
\text { Integration }\end{array}$ & $\begin{array}{l}1 \text { Degree of } \\
\text { Integration }\end{array}$ & Disassociated \\
\hline $\begin{array}{l}\text { The image takes on } \\
\text { the features of the } \\
\text { letter symbol. The } \\
\text { letter symbol does } \\
\text { not occupy the same } \\
\text { space. }\end{array}$ & $\begin{array}{l}\text { The image takes } \\
\text { on the features of } \\
\text { the letter symbol. } \\
\text { The letter symbol } \\
\text { occupies the same } \\
\text { space. }\end{array}$ & $\begin{array}{l}\text { The image takes on } \\
\text { some of the features } \\
\text { of the letter symbol. } \\
\text { The letter symbol } \\
\text { occupies the same } \\
\text { space. }\end{array}$ & $\begin{array}{l}\text { The image is in its } \\
\text { more natural state. } \\
\text { The letter symbol } \\
\text { occupies the same } \\
\text { space. }\end{array}$ & $\begin{array}{l}\text { The image is in its } \\
\text { more natural state. The } \\
\text { letter symbol does not } \\
\text { occupy the same space. }\end{array}$ \\
\hline
\end{tabular}

Figure1. Integration scale 


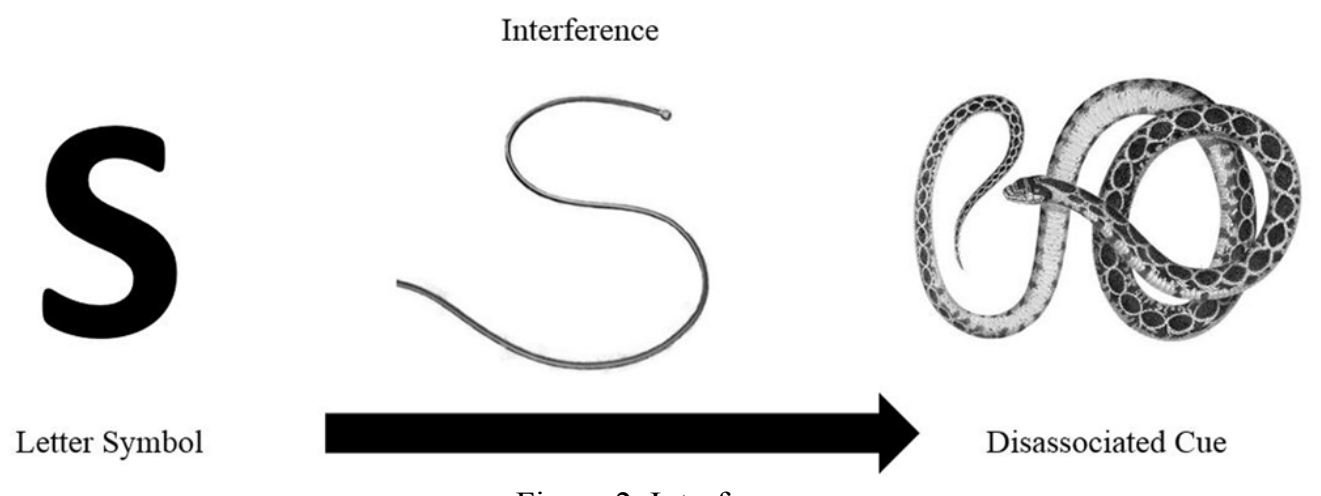

Figure 2. Interference

The scale found in Figure 1, produced by the authors, shows that pictorial mnemonics can vary in the degree to which an illustration can take on the form of its corresponding letter symbol. As we move along the scale from "form taking" to "disassociated", the mnemonic cue takes on less features of its matching letter symbol so that the link between image and letter becomes increasingly artificial. The problem with artificial links is that other memories may interfere with recall. For example, in Figure 2 we see that the letter $\mathrm{S}$ is similar in shape to the garden hose. Individuals who are reminded of this connection may be led to their memory of a hose, which may distract and inhibit their ability to arrive at their target memory. This distraction has been referred to as "interference" (Danker, Fincham, \& Anderson, 2011; Kline, 1921; Van Dyke \& Johns, 2012), which has been suggested as the main cause of "forgetting" target content (Levy \& Wagner, 2013, p. 3).

\subsubsection{Minimising Interference}

For centuries people have attempted to combat interference and to aid recall using two main types of organisational mnemonics; the peg-type mnemonic (use of numbers to aid the recall of information) and the chain-type mnemonic (the process used to recall a long list of items) (Bellezza, 1981; Levin, 1993). In both instances the aim is to unitise information into a connected, meaningful whole in memory so that retrieval is more ably facilitated (Bellezza, 1981). The chain-type mnemonic in particular can be thought of as a purposefully devised path that leads the learner from one piece of information to the next until one has arrived at the desired target, without being led astray by competing memories.

Designing an image to take on the shape of its corresponding letter symbol is a technique that aligns itself with the use of chain-type mnemonics. It has been suggested that some mnemonic devices, such as pegword mnemonics, have little or no connection to the concept being learned, resulting in many labelling this type of connection "artificial" (Bellezza, 1981). Artificially or "forcibly" integrating the shape of a letter into an image is an example of using two disparate concepts, in an attempt to aid recall. Moulding an image to take on the shape of a letter, using characteristics which both the image and the letter shape share creates a more concrete connection, which theoretically should be more effective at aiding recall while minimising potential distractors.

\subsection{Current Study}

The focus of most studies exploring the use of pictorial cues to facilitate the learning of letter sound associations has centred on establishing whether using an integrated mnemonic device is more effective than not. What these studies have not considered is whether mnemonic devices which attempt to make use of concrete links to common objects may prove more effective than those which seek to artificially manufacture such links. Five of the twelve listed studies compared the integrated mnemonic against the disassociated cue in an effort to establish relative effectiveness. Of these, four declared the integrated mnemonic more effective than the disassociated cue (Ehri et al., 1984; Manalo et al., 2013; Shmidman \& Ehri, 2010) (Note 3), with the fifth presenting with inconclusive results (de Graaff et al., 2009). Only two articles included the "form taking" pictorial mnemonic (Dilorenzo et al., 2011; Gregory, 1984). In both of those studies, form taking mnemonics were grouped with integrated mnemonics, with no reference to or distinction made between categories. We are also presented with an intriguing finding in that de Graaff et al. (2007) found that the printed integrated pictorial mnemonic was less effective than learning letter symbols in isolation by rote.

This study therefore, explored two avenues of enquiry: 
1) to investigate whether the design of the pictorial representations used in phonics applications (concrete [form taking] versus artificial [integrated]) may be a significant design feature of mobile applications designed for children learning common letter-sound matches in their first year of schooling; and

2) to investigate whether use of the phonics applications under trial were comparable to teacher-led drill and practice.

\section{Method}

This study utilised a paper-based pre and post-test (detailed under "data collection and analysis") conducted 12 weeks apart, to determine children's knowledge of the most common letter-sound associations before and after the trial period. The trial period took place over a 10-week period in the second term of a four-term school year.

\subsection{Mobile Application - A to Z Safari (Version 1.0; Nicholas, McKenzie, Spence, \& Wells, 2015)}

A to $Z$ Safari was designed to support interactive engagement with the English alphabet via games that ask students to match letter symbols to their most commonly associated unit of sound. A to Z Safari was designed for 5 to 7 year old children for use in the first-year classroom but can be used by any child who is ready to start learning letter-sound mapping. The font used in the applications was Victorian Modern Cursive as this was the font used in the trial school, as is the case with most government schools in the state of Victoria, Australia.

The design of A to Z Safari consisted of a welcome screen, two mini-games (match and memory); and an administration area where classroom teachers can create a class list and begin or end "assessment sessions" to enable the gathering of user statistics. To address our first research question, two versions of the mobile application were created and used in two trial first-year classrooms. One classroom used the mobile application with form taking pictorial cues (Figure 3). A second classroom used the same mobile application, however the pictorial mnemonics had been replaced with integrated pictorial cues (Figure 4).

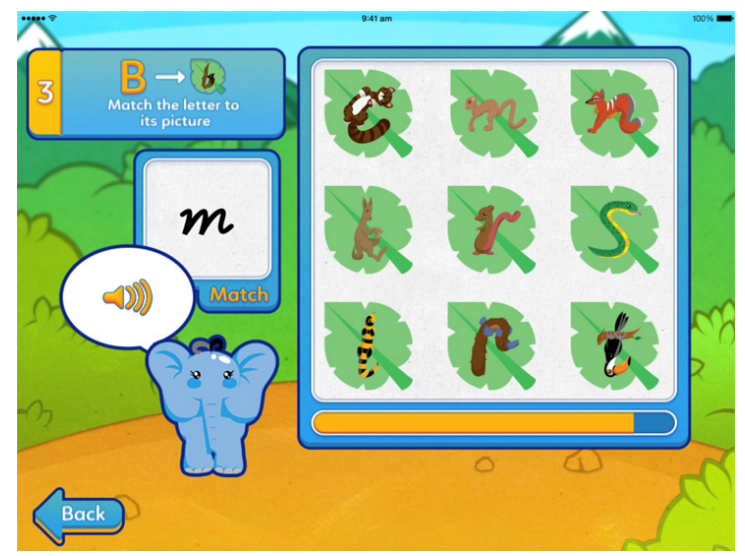

Figure 3. A match game using "form taking" picture cues

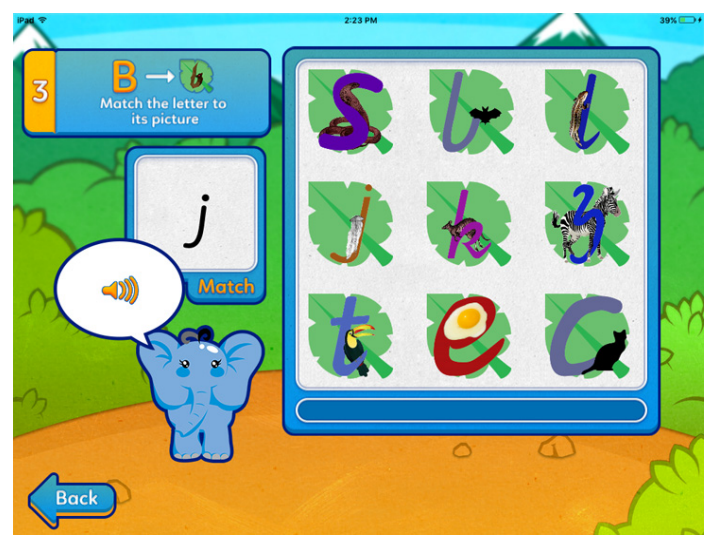

Figure 4. A match game using "integrated" picture cues 


\subsection{Participants}

The elementary school where the trial took place was located in the state of Victoria, Australia. The school had 270 students with an Index of Community Socio-Educational Advantage (ICSEA) rating of 958 (below the state mean of 1000), indicating that the students and their families were from a lower socio-economic background than many of their counterparts across the state. Twenty-two percent of the families enrolled at the school came from a Language Background Other Than English (LBOTE), which was representative of the percentage of LBOTE families present in each of the three first-year groups/classrooms that took part in the trial.

Three groups of first-year children ( $n=16$ in each group), ranging in age from 5-6 and their three teachers participated in this research. The groups can be described as:

a) FTC-SD: Children ( $\mathrm{n}=8$ males; $\mathrm{n}=8$ females) who used the self-directed mobile application which made use of form taking letter-picture cues (Figure 3);

b) IC-SD: Children ( $n=6$ males; $n=10$ females) who used a modified version of the self-directed application used by FTC-SD. The IC-SD version replaced the form taking images with integrated letter-picture cues. All other aspects/features of the application remained the same (Figure 4);

c) TLI: Teacher-led instruction. These children ( $\mathrm{n}=5$ males; $\mathrm{n}=11$ females); did not use tablet devices.

The FTC-SD class had one male student with a refugee background. He spoke minimal English at the commencement of the study but was able to identify the letter at the beginning of his name and its most commonly associated sound during the pre-test. All other LBOTE children across all three classes engaged in clear English oral communication at the commencement of the study. Each group is described in greater detail below.

\subsubsection{The Three Groups}

As detailed in their post-testing interview, the teachers of all three classes met weekly to ensure that they all had "the same letter and sight word focus for the week" (TLI-teacher). They would also touch on other letters already learnt as part of their teaching program. They ensured to watch the same alphabet song available online once a week.

We bring our ideas to the team. We then leave with all of those ideas and you can allocate what day you'd like to do those activities (TLI-teacher).

All three classes engaged in "guided reading" sessions where small groups of 3-5 children read teacher chosen texts targeted at their instructional reading level, with teacher guidance; and "reading rotations" where children engaged in reading and writing related activities at their tables, largely independently or with peer collaboration. All three classes had printed alphabet charts on their tables (strips with images and letters). The TLI class used disassociated images, the FTC-SD class made use of a strip with the same form taking images used in the Figure 3 phonics application. The IC-SD class had strips with integrated picture cues, as shown in Figure 4.

\subsubsection{Use of Devices}

One classroom used the FTC-SD digital application (Figure 3) while the other used the IC-SD application (Figure 4). Both groups had access to four iPads each, which allowed the children to use the tablets during small group tasks on a rotational basis, ensuring that each child was scheduled to use the iPad once a week. In both classrooms the teachers reported using the digital application in the first week of term as a teacher-led small group guided instruction session. The children needed some direction in the second week but following this, the children used the devices in a self-directed capacity as part of their "reading rotations". The teacher of the FTC-SD classroom commented that:

...we always checked with each other before we did anything just to make sure that the other person is doing the same.

\subsubsection{Teacher-Led Group}

In this classroom, as detailed by the teacher in the post-testing interview, there was a lot of teacher-led "rote" learning "...a lot of consistency of going over and over... until they get it" (TLI-teacher). Use of an alphabet song displayed on the interactive whiteboard would be accessed once a week whole class as with the other two classrooms, however the TLI-teacher's instruction differed to the other two groups in the following way: 
At the end all the [disassociated] pictures are up there... I write it [a letter symbol] over the [interactive] whiteboard with the picture because at the very end it shows all the pictures from the song ... whole class.

Beyond this, the TLI-teacher would direct the children to an alphabet wall with letters and disassociated image cues displayed in the classroom at least once a week:

When we go over it we do say it three times and I think it just helps to stick in their brain... up here on the board [word wall]. So we'd say "Y", /y/, /y/, /y/ ... "H", /h/, /h/, /h/, "M", /m/, /m/, /m/, so they were doing it all together... moving away from the song.

The letter symbols on the word wall were displayed randomly. TLI-teacher indicated that this was to ensure that children were not learning the letters in alphabetical order. Each child would also be asked to choose five letters that the class had already learnt, telling the teacher and whole class what the letter is, the sound it makes and a word that starts with that sound. They were then to choose a letter that hadn't yet been a focus letter, or to ask a friend for help:

Most kids choose the first letter of their name and so then that's teaching the other kids.

In addition to this weekly practice, the teacher indicated that she differed her approach to the other teachers by working with small groups of students who "were still struggling", for five minutes following her reading sessions. We have interpreted this to suggest that the teacher worked with small groups of children who were not learning letter-sound matches as quickly as their peers. This occurred three-five times per week, using cards with letters and disassociated images. The children were to identify the name of the letter, the most common sound the symbol represents, and words that begin with that sound.

\subsection{Data Collection and Analysis}

Each child in each group was assessed using a paper-based randomised letter-sound recognition test using the 26 letters of the English alphabet presented in Victorian Modern Cursive font. Children were asked to give the most common sound that each letter represents until they had given an answer for each letter or indicated that they did not know a particular letter/s yet. Children were assessed at the beginning of term 2 (entry data) and after 10 weeks, at the end of term 2 (exit data). Student scores were presented as totals (how many letter-sound matches did each child identify correctly?). The data in the results have been presented in aggregate (divided into quartiles, averages and via independent-samples t-tests), ensuring that the children are non-identifiable.

Within-group distribution of outcomes was calculated at the beginning of the testing period by dividing each group's outcomes into quartiles. An independent-samples t-test was carried out to identify whether differences between classes were of statistical significance before the trial period began. Another independent-samples t-test was conducted at the conclusion of the ten week trial to determine statistical significance between groups following the trial.

A focus group interview and individual interviews were conducted with teacher participants following the trial period to clarify which teaching approaches were similar and which approaches differed between classes throughout the trial, providing teachers the opportunity to give feedback about the applications' design features.

\section{Results}

The following tables show the data that was gathered using the pre and post-test student results.

Table 1. Entry score data: letter-sound knowledge divided into quartiles

\begin{tabular}{llll}
\hline & IC-SD & FTC-SD & TLI \\
\hline Min & 1.00 & 1.00 & 1.00 \\
1st quartile & 5.00 & 3.00 & 3.50 \\
median & 10.50 & 9.50 & 10.00 \\
3rd quartile & 13.50 & 15.00 & 17.00 \\
Max & 21.00 & 19.00 & 23.00 \\
AVERAGE & 9.88 & 9.56 & 10.19 \\
\hline
\end{tabular}


Table 2. Statistical significance: pre-test letter-sound knowledge

\begin{tabular}{|c|c|c|c|c|c|}
\hline & Mean & Observations & df & t Stat & $\mathrm{p}=$ \\
\hline FTC-SD & 9.563 & 16 & \multirow{2}{*}{29} & \multirow{2}{*}{-0.256} & \multirow{2}{*}{0.8} \\
\hline TLI & 10.188 & 16 & & & \\
\hline & Mean & Observations & df & t Stat & $\mathrm{p}=$ \\
\hline IC-SD & 9.875 & 16 & \multirow{2}{*}{29} & \multirow{2}{*}{0.130} & \multirow{2}{*}{0.897} \\
\hline TLI & 10.188 & 16 & & & \\
\hline & Mean & Observations & $\mathrm{df}$ & t Stat & $\mathrm{p}=$ \\
\hline FTC-SD & 9.563 & 16 & \multirow{2}{*}{30} & \multirow{2}{*}{0.142} & \multirow{2}{*}{0.888} \\
\hline IC-SD & 9.875 & 16 & & & \\
\hline
\end{tabular}

It cannot be assumed that students will enter their first year of schooling without any knowledge of letter-sound associations (Nicholas \& Paatsch, 2014). Further to this, the collection of entry data and project implementation occurred during the second school term, three months into the school year. Given none of the student participants included were new to their class, all child participants had been exposed to letter-sound mapping instruction (at least one focus letter a week) prior to the trial. This is reflected in Table 1 with a great spread of knowledge evident in all three classes at the commencement of the study. In all classes there was at least one child who only knew one letter-sound association along with children who knew 19 or more.

Table 1 shows that a quarter of the children from the FTC-SD group and a quarter from the TLI group knew 1-3 letter-sound associations. This was slightly lower than the IC-SD group's first quartile, which shows that a quarter of student knew 1-5 letter-sound associations. The TLI group had the highest performing fourth quartile. A quarter of the children from this class began the second term knowing 17-23 letter-sound associations. There was also a greater spread amongst this group's third quartile with a quarter of students knowing 10-17 letter sounds. The FTC-SD class had the poorest performing fourth quartile with a quarter of children knowing 15-19 letter-sound associations.

Though the TLI class had the highest average (10.188), and the FTC-SD group presented with the lowest average (9.56), Table 2 shows us that the differences in scores across the three classes were not of statistical significance. Following the 10 week trial, outcomes of statistical significance were found between two of these groups, as shown in Table 3.

Table 3. Statistical significance: exit letter-sound knowledge

\begin{tabular}{llllll}
\hline & Mean & Observations & $\mathrm{df}$ & $\mathrm{t}$ Stat & $\mathrm{p}=$ \\
\hline FTC-SD & 19.875 & 16 & 26 & -1.072 & 0.294 \\
TLI & 21.875 & 16 & & & $\mathrm{p}=$ \\
\hline & Mean & Observations & $\mathrm{df}$ & $\mathrm{t}$ Stat & 0.022 \\
\hline IC-SD & 17.438 & 16 & 27 & -2.431 & $\mathrm{p}=$ \\
TLI & 21.875 & 16 & & $\mathrm{t}$ Stat & 0.267 \\
\hline FTC-SD & Mean & Observations & $\mathrm{df}$ & -1.134 & \\
IC-SD & 19.875 & 16 & 30 & & \\
\hline
\end{tabular}

Table 3 shows that though the use of the FTC-SD digital application yielded a higher average than the IC-SD digital application, with FTC-SD children identifying on average 2 more letter-sound associations than their IC-SD peers, no significant difference was found between the two groups: $\mathrm{t}(30)=-1.134, \mathrm{p}=0.267$ (FTC-SD M $=19.875$; IC-SD $\mathrm{M}=17.438$ ). When comparing users of the FTC-SD digital application to the TLI group there is a similar gap between group average scores, with students from the TLI group identifying 2 more letter-sound 
associations than their FTC-SD peers: $\mathrm{t}(26)=-0.1 .072, \mathrm{p}=0.294$ (FTC-SD $\mathrm{M}=19.875$; TLI $\mathrm{M}=21.875$ ), which again indicates that there was no significant difference between the two groups.

Comparing the IC-SD group with the TLI group however, the difference in outcomes was found to be of statistical significance, with an average of 4 letters the difference between the two groups as a whole: $t(27)=$ $-2.431, \mathrm{p}=0.022$ (IC-SD M = 17.438; TLI M = 21.875).

\section{Discussion}

The results from this study suggest that the use of a self-directed digital application, designed to assist children to acquire knowledge in letter-sound mapping, can be as effective as teacher-led instruction, when the application makes use of more concrete, form taking pictorial cues. The self-directed use of a digital device may not prove to be as effective as teacher-led instruction, when the software application makes use of more artificially integrated picture cues.

The findings from this project also suggest that digital devices can be used by young children in classrooms independently of their teacher to effectively support the acquisition of constrained knowledge such as letter-sound mapping, via drill and practice type gaming applications. FTC-SD-teacher shared that the use of tablet devices in her classroom meant that:

There was a group that was really being focussed and working on their own which doesn't always happen when the teacher is working with one group in Prep [the "Preparatory" classroom-also known as "Foundation"], so they were really on task.

This is reflective of Stern (2014), Flewitt et al. (2014) and Jones (2009) who submit that a benefit of using digital devices is that they can offer opportunities for self-directed, independent and individualised learning due to the ways in which software can provide automatic feedback within a visually appealing context.

This is an important finding, suggesting that one use for the digital device in the classroom may be to integrate their use into the curriculum to allow teachers to devote more time to engaging children in tasks that require more open ended, contextualised, higher order thinking. There was also suggestion from FTC-SD-teacher that the use of one-to-one devices has the potential to be more effective than whole class drill and practice given that,

...there are always going to be the ones that just pick it up from listening, pick it up from reading at home, pick it up from doing their home cards and things and then there's the ones that don't do any of that, who don't tune in on the floor or don't do any practice at home and then they are the ones that really benefit from using something like this [the application]... it really helped the lower fraction stay on task a little bit more and learn some sounds.

With the outcomes of the IC-SD group not proving as effective as teacher-led instruction, this investigation highlights that digital devices will not facilitate positive outcomes on their own, suggesting that the design of the images used in phonics software applications may be a significant factor contributing to their successful integration in classrooms. The IC-SD application only differed to the FTC-SD application in its image cues; all other design features and functionalities were identical. This finding provides some support for the suggestion that the design of phonics applications is critical if used to support the self-directed acquisition of lower order, closed knowledge. Reflective of suggestions made by Kress and Van Leeuwen (2001) and Clark and Mayer (2011), when selecting applications for use in classrooms it is essential to consider whether discourses (here referring to theories of memory retention, interference and the use of pictorial mnemonics to successfully learn letter-sound mapping) have been actualised through the design of the chosen application in order to facilitate learning most effectively, along with engagement.

\subsection{Limitations}

Our child participants used the phonics applications under trial for 20 minutes, once a week for 10 weeks. This is significantly less than findings that suggest that the most effective phonological instruction lasts between 5 to 18 hours, with longer-lasting programs providing more positive, statistically significant results (Ehri et al., 2001). Our sample size was also small.

Time spent using the phonics applications was comparable to time spent whole class on rote learning in the teacher-led classroom, but did not include the additional time spent with small groups of children (15-20 minutes a week) who needed more support in the teacher-led group.

The outcomes of this trial study provides support for a longer lasting testing period, a larger sample size and requesting that teacher-led instruction be limited to the same amount of drill and practice as classrooms using digital applications, to investigate whether image design is as critical in phonics applications as we have 
surmised. Given the ethical implications of requesting that teachers limit time spent with students, it is unlikely that a more controlled study can be undertaken. However, longer testing periods with larger sample sizes are a possibility that merit further investigation.

\subsection{Conclusion}

The results of this study suggest that when comparing the use of a self-directed digital application designed to assist young children to acquire knowledge in letter-sound mapping with teacher-led instruction, an application that makes use of form taking pictorial cues can be as effective as teacher-led instruction. A digital application that makes use of integrated pictorial cues however will not prove as effective as teacher-led instruction, when young children are working as self-directed learners. This suggests that pictorial mnemonics are most helpful for children who are beginning to learn letter-sound associations, when there is a more concrete and meaningful relationship between the image cue and letter symbol, indicating that image design is a critical design feature when creating educational phonics applications.

This study makes a good case for the use of digital devices in early years classrooms to support and supplement holistic classroom practices that plan for and accommodate both lower order and higher order thinking (using both print and digital texts) from the first year of schooling. It also cautions educators to make use of their professional judgement when choosing the digital applications they wish to integrate into their curriculum. Choice needs to be informed by inquiry into whether the application is highly engaging, while also promoting the psychological activity required to facilitate learning (Clark \& Mayer, 2011). This necessitates consideration of whether there is an alignment between discourse and design (Kress \& Van Leeuwen, 2001).

\section{Acknowledgements}

We would like to acknowledge the contributions of Aaron Spence and Nathan Beattie (application design); Dr Shaun Bangay for your support; the Department of Education and Training (DET) school, teachers and child participants, and their parents; the School of Information Technology students (Deakin University) who participated in the preliminary design and programming phase of the project and Amy Peterson for her creation of the form-taking images used in the A to Z Safari (Nicholas et al., 2015) application. We would like to highlight that the views portrayed in this article are those of the authors and do not necessarily reflect views held by the DET or others listed in the acknowledgements.

\section{References}

Agramonte, V., \& Belfiore, P. J. (2002). Using Mnemonics to Increase Early Literacy Skills in Urban Kindergarten Students. Journal of Behavioural Education, 11(3), 181-190. https://dx.doi.org/10.1023/A:1020178020059

Australian Government: Department of Education, S. A. T. (2005). Teaching Reading-Report and Recommendations-National Inquiry into the Teaching of Literacy, December 2005. Australian Government: Department of Education, Science and Training. Retrieved from http://www.dest.gov.au/nitl/documents/report_recommendations.pdf

Bellezza, F. S. (1981). Mnemonic Devices: Classification, Characteristics, and Criteria. Review of Educational Research, 51(2), 247-275. https://dx.doi.org/10.3102/00346543051002247

Blackwell, C. K., Lauricella, A. R., \& Wartella, E. (2014). Factors Influencing Digital Technology Use in Early $\begin{array}{lllll}\text { Childhood } \quad \text { Education. } & \text { Computers } \& \text { Education, } & 77, & 82-90 .\end{array}$ https://dx.doi.org/10.1016/j.compedu.2014.04.013

Booker, M. J. (2007). A Roof without Walls: Benjamin Bloom's Taxonomy and the Misdirection of American Education. Academic Questions, 20(4), 347-355. https://dx.doi.org/10.1007/s12129-007-9031-9

Cassady, J. C., \& Smith, L. L. (2005). The Impact of a Structured Integrated Learning System on First-Grade Students' Reading Gains. Reading \& Writing Quarterly, 21(4), 361-376. https://dx.doi.org/10.1080/10573560591002277

Cheung, A. C., \& Slavin, R. E. (2012). How Features of Educational Technology Applications Affect Student Reading Outcomes: A Meta-Analysis. Educational Research Review, 7(3), 198-215. https://dx.doi.org/10.1016/j.edurev.2012.05.002

Clark, R. C., \& Mayer, R. E. (2011). E-learning and the science of instruction: Proven guidelines for consumers and designers of multimedia learning (3rd ed.). San Francisco, CA: Pfeiffer. https://dx.doi.org/10.1002/9781118255971 
Cobb, P. (1994). Where is the Mind? Constructivist and Sociocultural Perspectives on Mathematical Development. Educational researcher, 23(7), 13-20. https://dx.doi.org/10.3102/0013189X023007013

Danby, S., Davidson, C., Theobald, M., Scriven, B., Cobb-Moore, C., Houen, S., ... Thorpe, K. (2013). Talk in activity during young children's use of digital technologies at home. Australian Journal of Communication, 40(2). Retrieved from http://www.austjourcomm.org/index.php/ajc/article/view/4/122

Danker, J. F., Fincham, J. M., \& Anderson, J. R. (2011). The Neural Correlates of Competition during Memory Retrievel are Modulated by Attention to the Cues. Neuropsychologia, 49, 2427-2438. https://dx.doi.org/10.1016/j.neuropsychologia.2011.04.020

Darcy, R., \& Auld, G. (2008). The Production and Distribution of Burarra Talking Books. Australian Educational Computing, 23(1), 19-23.

de Graaff, S., Bosman, A. M., Hasselman, F., \& Verhoeven, L. (2009). Benefits of systematic phonics instruction. Scientific Studies of Reading, 13(4), 318-333. https://dx.doi.org/10.1080/10888430903001308

de Graaff, S., Verhoeven, L., Bosman, A. M. T., \& Hasselman, F. (2007). Integrated pictorial mnemonics and stimulus fading: Teaching kindergartners letter sounds. British Journal of Educational Psychology, 77, 519-539. https://dx.doi.org/10.1348/000709906X160011

De Grove, F., Bourgonjon, J., \& Van Looy, J. (2012). Digital games in the classroom? A contextual approach to teachers' adoption intention of digital games in formal education. Computers in Human behavior, 28(6), 2023-2033. https://dx.doi.org/10.1016/j.chb.2012.05.021

Dilorenzo, K. E., Rody, C. A., Bucholz, J. L., \& Brady, M. P. (2011). Teaching Letter-Sound Connections with Picture Mnemonics: Itchy's Alphabet and Early Decoding. Preventing School Failure, 55(1), 28-34. https://dx.doi.org/10.1080/10459880903286763

Ehri, L. C., Deffner, N. D., \& Wilce, L. S. (1984). Pictorial Mnemonics for Phonics. Journal of Educational Psychology, 76(5), 880-893. https://dx.doi.org/10.1037/0022-0663.76.5.880

Ehri, L. C., Nunes, S. R., Willows, D. M., Schuster, B. V., Yaghoub-Zadeh, Z., \& Shanahan, T. (2001). Phonemic awareness instruction helps children learn to read: Evidencen from the National Reading Panel's Meta-analysis. Reading Research Quarterly, 36(3), 250-287. https://dx.doi.org/10.1598/RRQ.36.3.2

Flewitt, R., Messer, D., \& Kucirkova, N. (2014). New directions for early literacy in a digital age: The iPad. Journal of Early Childhood Literacy, 1-22.

Fulk, B. M., Lohman, D., \& Belfiore, P. J. (1997). Effects of Integrated Picture Mnemonics on the Letter Recognition and Letter-Sound Acquisition of Transitional First-Grade Students with Special Needs. Learning Disability Quarterly, 20(1), 33-42. https://dx.doi.org/10.2307/1511091

Given, L. M., Winkler, D. C., Willson, R., Davidson, C., Danby, S., \& Thorpe, K. (2014). Documenting young children's technology use: Observations in the home. Proceedings of the American Society for Information Science and Technology, 51(1), 1-9. https://dx.doi.org/10.1002/meet.2014.14505101028

Gontijo, P. F. D., Gontijo, I., \& Shillcock, R. (2003). Grapheme-Phoneme Probabilities in British English. Behaviour Research Methods, Instruments and Computers Psychonomic Society, Inc., 31(1), 136-157. https://dx.doi.org/10.3758/BF03195506

Gregory, R. P. (1984). An Aid to Learning Letter-Sound Correspondences. School Psychology International, 5 , 224-232. https://dx.doi.org/10.1177/0143034384054007

Hedberg, J. G. (2011). Towards a Disruptive Pedagogy: Changing Classroom Practice with Technologies and Digital Content. Educational Media International, 48(1), 1-16. https://dx.doi.org/10.1080/09523987.2011.549673

Høien, T., Lundberg, I., Stanovich, K. E., \& Bjaalid, I. K. (1995). Components of Phonological Awareness. Reading and Writing, 7(2), 171-188. https://dx.doi.org/10.1007/BF01027184

Hoogeveen, F. R., Smeets, P. M., \& Lancioni, G. E. (1989). Teaching moderately mentally retarded children basic reading skills. Research in Developmental Disabilities, 10(1), 1-18. https://dx.doi.org/10.1016/0891-4222(89)90025-5

Hulme, C., Hatcher, P. J., Nation, K., Brown, A., Adams, J., \& Stuart, G. (2002). Phoneme awareness is a better predictor of early reading skill than onset-rime awareness. Journal of Experimental Child Psychology, 82(1), 2-28. https://dx.doi.org/10.1006/jecp.2002.2670 
Ihmeideh, F. M. (2014). The Effect of Electronic Books on Enhancing Emergent Literacy Skills of Pre-School Children. Computers \& Education, 79, 40-48. https://dx.doi.org/10.1016/j.compedu.2014.07.008

Jones, D. (Producer). (2009). A history of technology-mediated learning. The Weblog of (a) David Jones: A pessimistic optimist's journey through learning, teaching and technology. Retrieved from http://davidtjones.wordpress.com/2009/04/17/a-history-of-technology-mediated-learning/

Jongejan, W., Verhoeven, L., \& Siegel, L. S. (2007). Predictors of Reading and Spelling Abilities in First- and Second-Language Learners. Journal of Educational Psychology, 99(4), 835-851. https://dx.doi.org/10.1037/0022-0663.99.4.835

Joseph, L., Eveleigh, E., Konrad, M., Neef, N., \& Volpe, R. (2012). Comparison of the Efficiency of Two Flashcard Drill Methods on Children's Reading Performance. Journal of Applied School Psychology, 28(4), 317-337. https://dx.doi.org/10.1080/15377903.2012.669742

Kartal, G., \& Terziyan, T. (2016). Development and evaluation of game-like phonological awareness software for kindergarteners: JerenAli. Journal of Educational Computing Research, 53(4), 519-539. https://dx.doi.org/10.1177/0735633115608397

Kirriemuir, J., \& McFarlane, A. (2006). Literature Review in Games and Learning REPORT 8. Retrieved from http://www.futurelab.org.uk

Kline, L. W. (1921). An Experimental Study of Associative Inhibition. Journal of Experimental Psychology, 4(4), 270-299. https://dx.doi.org/10.1037/h0071479

Korat, O., \& Blau, H. (2010). Repeated reading of CD-ROM storybook as a support for emergent literacy: A developmental perspective in two SES groups. Journal of Educational Computing Research, 43(4), 445-466. https://dx.doi.org/10.2190/EC.43.4.b

Kress, G. R., \& Van Leeuwen, T. (2001). Multimodal discourse: The modes and media of contemporary communication. London: Arnold.

Kuo, M. L. A., \& Hooper, S. (2004). The effects of Visual and Verbal Coding Mnemonics on Learning Chinese Characters in Computer-Based Instruction. Educational Technology, Research and Development, 52(3), 23-38. https://dx.doi.org/10.1007/BF02504673

Landry, S. H., Swank, P. R., Anthony, J. L., \& Assel, M. A. (2011). An Experimental Study Evaluating Professional Development Activities within a State Funded Pre-Kindergarten Program. Reading and Writing, 24(8), 971-1010. https://dx.doi.org/10.1007/s11145-010-9243-1

Levin, J. R. (1993). Mnemonic Strategies and Classroom Learning: A Twenty-Year Report Card. The Elementary School Journal, 94(2), 235-244. https://dx.doi.org/10.1086/461763

Levy, B. J., \& Wagner, A. D. (2013). Measuring Memory Reactivation with Functional MRI: Implications for $\begin{array}{llllll}\text { Psychological Theory. Perspectives on Psychological Science, 8(1), } & \text { 72-78. }\end{array}$ https://dx.doi.org/10.1177/1745691612469031

Macaruso, P., \& Walker, A. (2008). The Efficacy of Computer-Assisted Instruction for Advancing Literacy Skills in Kindergarten Children. Reading Psychology, 29(3), 266-287. https://dx.doi.org/10.1080/02702710801982019

Manalo, E., Uesaka, Y., \& Sekitani, K. (2013). Using Mnemonic Images and Explicit Sound Contrasting to Help Japanese Children Learn English Alphabet Sounds. Journal of Applied Research in Memory and Cognition, 2(4), 216-221. https://dx.doi.org/10.1016/j.jarmac.2013.09.003

McManis, L. D., \& Gunnewig, S. B. (2012). Finding the education in educational technology with early learners. YC Young Children, 67(3), 14-24.

Melby-Lervåg, M., Lyster, S. A. H., \& Hulme, C. (2012). Phonological skills and their role in learning to read: A meta-analytic review. Psychological Bulletin, 138(2), 322-352. https://dx.doi.org/10.1037/a0026744

Musti-Rao, S., Lo, Y. Y., \& Plati, E. (2014). Using an iPad® App to Improve Sight Word Reading Fluency for At-Risk First Graders. Remedial and Special Education, 36(3), 154-166. https://dx.doi.org/10.1177/0741932514541485

Muter, V., Hulme, C., Snowling, M., \& Taylor, S. (1998). Segmentation, not Rhyming, Predicts Early Progress in Learning to Read. Journal of Experimental Child Psychology, 71(1), 3-27. https://dx.doi.org/10.1006/jecp.1998.2453 
National Early Literacy Panel. (2008). Developing Early Literacy: Report of the National Early Literacy Panel. A Scientific Synthesis of Early Literacy Development and Implications for Intervention. Jessup, MD: National Institute for Literacy. Retrieved from http://eric.ed.gov/?id=ED508381

National Reading Panel, N. (2000). Teaching Children to Read: An Evidence-Based Assessment of the Scientific Research Literature on Reading and its Implications for Reading Instruction: Reports of the Subgroups. Retrieved from http://www.nichd.nih.gov/publications/nrp/upload/report.pdf

Neumann, M. M. (2016). Young Children's Use of Touch Screen Tablets for Writing and Reading at Home: Relationships with Emergent Literacy. Computers \& Education, 97, 61-68. https://dx.doi.org/10.1016/j.compedu.2016.02.013

Nicholas, M., \& Paatsch, L. (2014). Teacher Practice: A Spotlight on the Use of Feedback and Conferencing in the First Year of Schooling. Australian Journal of Teacher Education, 39(9), 130-152. https://dx.doi.org/10.14221/ajte.2014v39n9.10

Nicholas, M., McKenzie, S., Spence, A., \& Wells, M. (Producer). (2015). A to Z Safari. Retrieved from https://itunes.apple.com/au/app/a-to-z-safari/id1031112949?mt=8

Nicolson, R., Fawcett, A., \& Nicolson, M. (2000). Evaluation of a computer-based reading intervention in infant and junior schools. Journal of Research in Reading, 23(2), 194-209. https://dx.doi.org/10.1111/1467-9817.00114

Noorhidawati, A., Ghalebandi, S. G., \& Hajar, R. S. (2015). How do Young Children Engage with Mobile Apps? Cognitive, Psychomotor, and Affective Perspective. Computers \& Education, 87, 385-395. https://dx.doi.org/10.1016/j.compedu.2015.07.005

Paivio, A., \& Csapo, K. (1973). Picture Superiority in Free Recall: Imagery or Dual Coding? Cognitive Psychology, 5, 176-206. https://dx.doi.org/10.1016/0010-0285(73)90032-7

Paterson, W. A., Henry, J. J., O'Quin, K., Ceprano, M. A., \& Blue, E. V. (2003). Investigating the Effectiveness of an Integrated Learning System on Early Emergent Readers. Reading Research Quarterly, 38(2), 172-207. https://dx.doi.org/10.1598/RRQ.38.2.2

Perfetti, C. A. (1991). Representations and Awareness in the Acquisition of Reading Competence. In L. Rieben, \& C. A. Perfetti (Eds.), Learning to read: Basic research and its implications (pp. 33-46). New York: Routledge: Taylor \& Francis Group.

Pfost, M., Hattie, J., Dörfler, T., \& Artelt, C. (2014). Individual Differences in Reading Development: A Review of 25 Years of Empirical Research on Matthew Effects in Reading. Review of Educational Research, 84(2), 203-244. https://dx.doi.org/10.3102/0034654313509492

Reid, D., \& Ostashewski, N. (2011). iPads in the Classroom-New Technologies, Old Issues: Are they worth the effort? Paper presented at the World Conference on Educational Multimedia, Hypermedia and Telecommunications.

Rowe, K. (2005). Teaching reading: Report and recommendations. Australian Government Department of Education, Science, and Training: National Inquiry into the Teaching of Literacy.

Sadoski, M., \& Paivio, A. (2013). Imagery and text: A dual coding theory of reading and writing. New York: Routledge.

Seaman, M. (2011). Bloom's Taxonomy: Its Evolution, Revision, and Use in the Field of Education. Curriculum and Teaching Dialogue, 13(1\&2), 29-43.

Sener, U., \& Belfiore, P. J. (2005). Mnemonics Strategy Development: Improving Alphabetic Understanding in Turkish Students, at Risk for Failure in EFL Settings. Journal of Behavioural Education, 14(2), 105-115. https://dx.doi.org/10.1007/s10864-005-2705-x

Shmidman, A., \& Ehri, L. (2010). Embedded Picture Mnemonics to Learn Letters. Scientific Studies of Reading, 14(2), 159-182. https://dx.doi.org/10.1080/10888430903117492

Stanovich, K. (1986). Matthew effects in reading: Some consequences of individual differences in the acquisition of literacy. Reading Research Quarterly, 21(4), 360-407. https://dx.doi.org/10.1598/RRQ.21.4.1

Stecchini, L. (1961). The Origin of the Alphabet. American Behavioural Scientist, 4(3), 3-7. https://dx.doi.org/10.1177/000276426100400601 
Stern, J. (2014). Digital classroom magazines: Design considerations for young learners. Paper presented at the CHI'14 Extended Abstracts on Human Factors in Computing Systems. https://dx.doi.org/10.1145/2559206.2579412

Tournaki, N. (2003). The differential effects of teaching addition through strategy instruction versus drill and practice to students with and without learning disabilities. Journal of Learning Disabilities, 36(5), 449-458. https://dx.doi.org/10.1177/00222194030360050601

Van Dyke, J. A., \& Johns, C. L. (2012). Memory interference as a determinant of language comprehension. Language and Linguistics Compass, 6(4), 193-211. https://dx.doi.org/10.1002//nc3.330

Walsh, M. (2011). Multimodal Literacy: Researching Classroom Practice. Newtown, NSW, Australia: Primary English Teaching Association.

Watlington, D. (2011). Using iPod touch and ipad educational apps in the classroom. Paper presented at the Society for Information Technology \& Teacher Education International Conference, United States.

Yu, F. Y., Liu, Y. H., \& Chan, T. W. (2005). A Web-Based Learning System for Question-Posing and Peer Assessment. Innovations in Education and Teaching International, 42(4), 337-348. https://dx.doi.org/10.1080/14703290500062557

\section{Notes}

1) In this paper we refer to the most "commonly used letter-sounds" for each of the 26 letters of the British English alphabet (Gontijo, Gontijo, \& Shillcock, 2003), rather than every sound that every letter can represent on its own or in combination with others; a starting point used to initiate a child's awareness of letter-sound mapping.

2) Gregory's (1984) article is a descriptive report. No data has been provided to support his discussion.

3) Ehri et al. (1984) details two separate experiments in the one article.

\section{Copyrights}

Copyright for this article is retained by the author(s), with first publication rights granted to the journal.

This is an open-access article distributed under the terms and conditions of the Creative Commons Attribution license (http://creativecommons.org/licenses/by/4.0/). 